\title{
EDUCAÇÃO EMPREENDEDORA E CULTURA DIGITAL: UM ESTUDO NO WEBSITE DA ENDEAVOR BRASIL
}

\section{INTRODUÇÃO}

\author{
Carina Nunes ${ }^{1}$ \\ Nicole Vitor Gomes ${ }^{2}$ \\ Carla Spillere Busarello ${ }^{3}$ \\ Melissa Watanabe ${ }^{4}$
}

É possível perceber um grande avanço nas metodologias de ensino e de difusão do conhecimento na internet. Atualmente se encontram inúmeras plataformas de educação à distância. Neste contexto Buckingham (2010) ressalta 0 papel que os recursos digitais vêm desempenhando na vida das pessoas e a importância das novas abordagens de aprendizagem na cultura digital. Vivencia-se assim, um período marcado pelo uso de tecnologias na difusão de conhecimentos no meio digital, decorrente de interações online, na chamada sociedade em rede (CASTELLS,1999). A ideia de rede é apresentada por Pretto e Assis (2008) com o próprio significado da palavra, a qual derivada do latim retis refere-se a um emaranhado de fios entrelaçados. Já no panorama tecnológico esse conceito é remetido à produção de informações e a apropriação da cultura digital, passando a ser cruciais no processo de reorganização dos modos de aprendizagem. Assim, as comunidades online servem de espaço para criação e inovação, articulando-se de maneira global à medida que seu modelo pedagógico é estruturado (DIAS, 2012).

Percebe-se que os formatos de aprendizagem no meio digital, carecem do desenvolvimento de ferramentas criativas as quais possibilitam o acesso às informações em tempo real, dependendo para tanto, da experiência vivenciada por seus usuários. Corroborando ao desenvolvimento de tais tecnologias, Silva, Duarte e Souza (2013) apresentam espaços de virtualização capazes de aproximar pessoas e criar oportunidades de colaboração entre grupos. Assim, a Sociedade em Rede, permite conexões simultâneas entre pessoas de diversas localidades, ultrapassando

\footnotetext{
${ }^{1}$ Graduanda em Administração de Empresas pela Universidade do Extremo Sul Catarinense (UNESC), carinanunes@unesc.net.

${ }^{2}$ Mestranda do Programa de Pós-Graduação em Desenvolvimento Socioeconômico da Universidade do Extremo Sul Catarinense (UNESC), nicole@unesc.net.

${ }^{3}$ Mestranda do Programa de Pós-Graduação em Desenvolvimento Socioeconômico da Universidade do Extremo Sul Catarinense (UNESC), carlabusarello@unesc.net.

${ }^{4}$ Docente Permanente do Programa de Pós-Graduação em Desenvolvimento Socioeconômico da Universidade do Extremo Sul Catarinense (UNESC), melissa@unesc.net.
} 
fronteiras territoriais em decorrência da utilização das Tecnologias de Informação e Comunicação (TIC) (CASTELLS,1999). E ainda, trata-se de um canal no qual os usuários podem se expressar e aumentar sua criatividade (LÉVY, 2000).

Em meio ao cenário apresentado, surge ainda a figura do empreendedor e o aumento no interesse em conteúdos voltados à educação empreendera. $\mathrm{O}$ entendimento que orienta a elaboração deste trabalho parte de Souza, Moura e Silva (2013, p.701) deste modo, entende-se a "educação empreendedora como impulsionadora do desenvolvimento social, tendo em vista promover nos alunos atitudes, e habilidades para agirem de forma empreendedora".

O contexto empreendedor em meio à cultura digital é fortemente representado pela Endeavor. Uma organização mundial, sediada em Nova lorque, nos Estados Unidos, nascida com intuito de auxiliar no crescimento econômico em longo prazo, dando suporte e apoio intelectual à empresas emergentes, proporcionando-Ihes ensino e capacitação. Uma das ferramentas utilizadas pela organização para atingir seus objetivos são distribuídos, justamente, por meio de suas plataformas online (ENDEAVOR, 2016).

O objetivo desta pesquisa é analisar os conteúdos disponíveis no website da Endeavor Brasil, verificando de que maneira a organização interage com os seus usuários para difundir a cultura empreendedora a qual se propõe.

\section{ENDEAVOR GLOBAL ${ }^{5}$}

Os fundadores da Endeavor compartilhavam de aspirações acerca de um modelo de negócios inovador e disruptivo, visando promover desenvolvimento socioeconômico em mercados emergentes. Começando pela América Latina, os idealizadores Linda Rottenberg e Peter Kellner, se questionavam porque os países em desenvolvimento não apostavam no empreendedorismo como fonte desenvolvimento econômico. Após muita investigação Linda e Peter chegaram à conclusão de que existiam pessoas altamente capacitadas para empreender, porém com pouco estímulo e falta de mentores que pudessem auxiliá-los a alavancarem seus empreendimentos ou ideias.

\footnotetext{
${ }^{5} \mathrm{O}$ histórico da Endeavor Global foi organizado de acordo com os dados disponibilizados no site http://endeavor.org.
} 
O primeiro escritório da Endeavor foi instalado em Nova lorque, Estados Unidos em 1997, e desde então a organização atua identificando os melhores empreendedores e fornecendo orientação e possibilidades de reais de crescimento sustentável para esses empreendedores. Além promover aceleração de negócios, a empresa também proporciona, aos empreendedores e outros indivíduos que possuam interesse, uma série de conteúdos didáticos e consultorias, os quais auxiliam na gestão e promoção de práticas inovadoras.

A Endeavor criou um modelo que permite selecionar, apoiar, multiplicar, devolver e sustentar movimentos de empreendedores de alto impacto ao redor do mundo. A organização nasceu para promover a cultura empreendedora entre os membros de uma comunidade, bem como multiplicar o número de empreendedores de alto crescimento e criar um ambiente de negócios melhor para os países em que atua. Deste modo destaca-se o fato de tal organização utilizar princípios de expansão inovadores pautados nas lógicas da sociedade em rede. No ano de 2000 a Endeavor chegou ao Brasil ${ }^{6}$, e já conta com oito escritórios espalhados pelo país. De acordo com a própria organização, ela:

existe para multiplicar o número de empreendedores de alto crescimento e criar um ambiente de negócios melhor para o Brasil. Por isso, selecionamos e apoiamos os melhores empreendedores, compartilhamos suas histórias e aprendizados, e promovemos estudos para entender e direcionar o ecossistema empreendedor no país (ENDEAVOR, 2016).

Dentre as metodologias de ensino utilizadas pela empresa via plataforma online estão disponíveis, principalmente, vídeos, artigos, cursos, e e-books. E o objetivo neste sentido é inspirar e capacitar empreendedores a serem mais assertivos e alavancarem seus negócios.

\section{PROCEDIMENTOS METODOLÓGICOS}

Com intuito de analisar os conteúdos disponíveis no website da Endeavor Brasil e verificar de que maneira a organização interage com os seus usuários, realizou-se um pesquisa qualitativa, exploratória e descritiva. A partir de dados secundários coletados diretamente na página web da Endeavor Brasil por meio do domínio http://endeavor.org.br/ em 26 de fevereiro de 2016. Buscou-se assim

\footnotetext{
${ }^{6}$ Os dados referentes a Endeavor Brasil, estão disponíveis a partir do link http://endeavor.org.br/.
} 
explorar a página principal do website e, os caminhos de navegação nele disponíveis. Os procedimentos de análise foram divididos em duas etapas, permitindo assim a categorização dos conteúdos para análise.

Etapa 1: análise da página principal do website da Endeavor Brasil.

- Primeiro momento: verificação dos hiperlinks de acesso rápido a conteúdos em destaque;

- Segundo momento: organizaram-se os conteúdos em três eixos, conforme apareciam na página: (a) Explore, (b) + Planejamento Estratégico e (c) Destaques.

Etapa 2: Destinou-se a análise dos menus (principal e secundários).

\section{RESULTADOS E DISCUSSÕES}

\section{Interface Gráfica: página principal do website Endeavor Brasil}

O momento inicial da primeira etapa segue um critério de organização e análise dos dados obtidos no website da Endeavor Brasil, buscando identificar os conteúdos de acesso rápido enfatizados na página. Assim, logo ao entrar na interface o usuário é instigado a saber mais sobre determinados assuntos. A pesquisa revelou quatro abas de destaque para esse seguimento: a) envie suas dúvidas e participe ao vivo; b) conheça nosso programa de apoio a empreendedores; c) o sonho grande de salvar vidas emitindo radiação; e, d) o ano já começou, coloque a leitura em dia com essas dicas.

No item (a), envie suas dúvidas e participe ao vivo, o usuário pode acessar uma mentoria online, na qual é possível participar ao vivo fazendo pergunta pertinente ao tema, porém, para aqueles que não puderam participar, a Endeavor disponibiliza o vídeo que foi desenvolvido no dia do evento.

Lógicas semelhantes ao que ocorre nas mentorias se aplicam aos demais recursos disponibilizados pela organização. $\mathrm{Na}$ aba (b), conheça nosso programa de apoio a empreendedores o usuário é direcionado para "Endeavor promessas", um programa para aceleramento de empresas com duração de sete meses, e, que proporciona aos selecionados mentorias e reuniões coletivas ou individuais com foco 
na resolução de problemas pertinentes ao seu negócio. O programa possui três eixos principais de atuação: capacitação, networking e conexão. Para fazer parte deste programa os interessados devem atender a alguns critérios de seleção ${ }^{7}$, préestabelecidos pela Endeavor, por meio do preenchimento de um formulário online. Inerente ao processo de prospectar empreendedores a participarem do programa, a organização apresenta relatos de outros empresários que já participaram e obtiverem os resultados positivos, bem como o perfil de alguns dos mentores que fazem parte da rede.

Dentre as áreas empresariais, as quais podem ser abordadas e trabalhadas nos empreendimentos estão: vendas, marketing, finanças, gestão, acesso a investidores e modelos de negócios. É possível perceber um alto grau de comprometimento com o programa, tanto das pessoas que participam como aceleradas quanto dos mentores, e cada processo é individual e personalizado o elevava ainda mais o envolvimento dos empreendedores participantes. Neste programa o website limita-se a prospecção de novos mentorados para a rede, os quais farão acompanhamento direto com a empresa.

A aba (c), o sonho grande de salvar vidas emitindo radiação, apresenta um vídeo inspirador, contando rapidamente a história de superação de um empreendedor, neste quesito a plataforma web é utilizada para transmitir histórias reais como fontes de incentivo.

Em (d), o ano já começou, coloque a leitura em dia com essas dicas, há um artigo com várias dicas de leituras, nas quais as referências bibliográficas destacam-se na área do empreendedorismo. Na página a qual o leitor é direcionado, estão disponíveis os assuntos abordados nos livros, estas literaturas não são disponíveis para download.

Ainda na primeira etapa de análise, porém no segundo momento identificou-se uma ordem de organização da página inicial (home), possibilitando perceber três colunas com conteúdos distintos, representadas por: 1) Explore; 2) + Planejamento Estratégico; e 3) Destaques.

$\mathrm{Na}$ coluna (1) Explore, foram identificados sete elementos, representados pela ordem: i) receba os melhores conteúdos de empreendedor para empreendedor;

\footnotetext{
${ }^{7}$ Os critérios de seleção podem ser visualizados a partir no site da Endeavor, por meio do link http://programapromessas.endeavor.org.br/\#page-block-n4x7nb9nok7ta9k9.
} 
ii) Check-up Endeavor, iii) Perfil Empreendedor; iv) Doe para Endeavor, v) E-books gratuitos, vi) Ambiente Empreendedor; e, vii) Mais visitados do mês.

O elemento (i) receba os melhores conteúdos de empreendedor para empreendedor apresenta um modo de conexão da organização por meio de redes sociais, na qual o usuário cadastra o seu o e-mail passando a receber informações por correio eletrônico, e também têm a opção de compartilhar os conteúdos com outros usuários. Assim organização começa a se conectar com os usuários de maneira individual e torna-se capaz de aumentar sua rede de contatos e poder de impacto.

O (ii) Check-up Endeavor, é uma ferramenta em formato de quiz, no qual os empreendedores são direcionados a refletirem sobre dados dos seus próprios empreendimentos, a medida na qual seguem preenchendo um formulário. Esta ferramenta aborda uma metodologia capaz de analisar os empreendimentos considerando as respostas apresentadas. O mecanismo considera o ponto do ciclo de vida em que o empreendimento se encontra e gera um diagnóstico, indicando os conteúdos específicos, que melhor se adequem a realidade dos empreendedores, estes arquivos são enviados para a conta de e-mail, cadastrada, permitindo assim capacitação personalizada. Ao término do diagnóstico, dentre outras opções, é possível indicar para um amigo, salvar o arquivo gerado em PDF, compartilhar em redes sociais.

No (iii) Perfil Empreendedor há um quiz destinado a verificar o perfil dos empreendedores, ao clicar sobre o hiperlink o usuário pode preencher o formulário online, ou então escolher a opção de fazer download da pesquisa completa. Optando por preencher o formulário o usuário pode dar início ao teste e, será direcionado à página na qual vai identificar os itens que mais se adequem à sua realidade. Após responder vinte questões de múltipla escolha é apresentado o resultado do perfil empreendedor do indivíduo e, também algumas dicas para que 0 empreendedor crie condições de se aperfeiçoar em conhecimentos específicos necessários. Optando apenas por fazer o download da pesquisa sem responder o teste, o usuário é remetido à página "Cultura Empreendedora no Brasil", na qual irá se cadastrar e já poderá acessar um arquivo no formato PDF.

O mecanismo utilizado por esse sistema se faz inspirador, e vale destacar o método no qual são direcionados conteúdos para a conta de e-mail, do usuário, com lições fundamentadas no resultado do teste. $O$ teste proporciona ao indivíduo 
respostas que lhe permitem buscar aperfeiçoamento pessoal e autoconhecimento para melhor aplicar em seus negócios.

É possível fazer uma doação para Endeavor clicando-se em (iv) Doe para Endeavor. À medida que o usuário clica na opção para fazer uma doação ele é remetido à página de campanhas, e lá abre uma janela com a seguinte mensagem: "Não pode doar hoje? Você pode colaborar com essa campanha divulgando nas suas mídias sociais" aí é possível selecionar, facebook, twiter e email dentre várias outras. Destaca-se a transparência do processo e o modo como as pessoas podem ajudar, se não financeiramente, então compartilhando os conteúdos nas redes sociais, possibilitando que mais pessoas tenham conhecimento de causa sobre quem é o que faz a Endeavor.

O elemento (v) E-books gratuitos apresenta um hall de conteúdos, os quais podem ser compartilhados em rede com outros usuários, ou feito download do arquivo. São variados materiais didáticos, direcionados a pontos estratégicos de gestão para empreendimentos. Foram identificados vinte e dois títulos disponíveis gratuitamente aos usuários. Dentre os seguimentos, de marketing, liderança, gestão de pessoas, vendas, finanças e acesso à investidores, dentre muitos outros.

Relacionados ao (vi) Ambiente Empreendedor, o usuário é direcionado a uma página na qual são elencados inúmeros dados relativos a pesquisas realizadas pela Endeavor e parceiros, entre essas pesquisas há o índice de cidades empreendedoras $2015^{8}$, no qual são abordados uma série de informações, que servem, não apenas para a abertura de novos negócios, mas também como ferramenta de gestão auxiliando de fato no planejamento de negócios, a medida que é baseado em temáticas como: ambiente regulatório, infraestrutura, mercado, acesso a capital, inovação, capital humano e cultura. Também tem outros materiais disponíveis, tais como: estatísticas de empreendedorismo; empreendedorismo nas universidades; scale-ups no Brasil; observatório do empreendedorismo; cultura empreendedora no Brasil; empreendedores brasileiros; Rio de Janeiro empreendedor; como o Vale do Silício se tornou o Vale do Silício, entre outras.

O último tópico da coluna (1) Explore, é o item (vii) que corresponde aos Mais visitados do mês, neste elemento é possível identificar os arquivos mais acessados, ou que mais ajudaram pessoas. O exemplo do exposto é possível citar

\footnotetext{
${ }^{8}$ Material elaborado em parceria da Endeavor Brasil e o Sebrae (Serviço brasileiro de apoio às micro e pequenas empresas.
} 
o título 5H2H: hora de tirar as dúvidas e colocar a produtividade no seu dia a dia postado em junho de 2015, cujo as visualizações ultrapassam treze mil acessos.

A segunda coluna, identificada na página inicial do website é formada por (2) + Planejamento Estratégico, no qual foram discriminados duas categorias de conteúdos: (viii) Artigos; e (ix) Trilha de e-mails: Planejamento estratégico para empreendedores. Na categoria (viii) Artigos é possível localizar trabalhos referentes aos mais variados assuntos em empreendedorismo com função de auxiliar o empreendedor no planejamento estratégico e de boas práticas de gestão para os empreendimentos. Bem como materiais os quais descrevem ferramentas de gestão que podem ser utilizadas pelos empreendedores para melhoras suas organizações.

O elemento (ix) compõe a Trilha de E-mails: Planejamento Estratégico para Empreendedores, no qual, ao se inscrever o participante do programa pode escolher com que frequência e qual a variedade de conteúdos gostaria de receber por e-mail, as quais irão auxilia-lo a responder alguns questionamentos de seu interesse e os quais deseja se aperfeiçoar, tais como: infraestrutura, mercado, cultura empreendedora, inovação, ambiente regulatório, capital humano, acesso a capital, melhor momento para planejar; métodos a serem utilizados; etapas de desenvolvimento a serem seguidas; e, como transformar os planejado em realizado.

O último eixo desta etapa é formado por (3) Destaques, no qual foram identificadas duas categorias de conteúdos: (x) Artigos; e (xi) Cursos online. Este elemento representa tudo àquilo que é novidade na página da Endeavor, sejam vídeos, eventos, mentorias, ofertas de cursos, entre outros. Os cursos online são disponibilizados aos usuários gratuitamente e são formatados de acordo com áreas específicas na empresa por meio de uma plataforma de ensino à distância, com textos e vídeo aulas.

\section{Navegando pelos Menus: principal e secundário}

A segunda etapa desta pesquisa destinou-se a analisar os menus: principal e secundários, os quais aparecem na parte superior da página principal do website da Endeavor Brasil. Ao lado dos menus estão dispostas as opções Login/Cadastro e uma ferramenta de busca rápida. Essas opções permitem ao usuário, respectivamente, cadastrar e-mail e senha, para terem um acesso personalizado à rede e assim ficarem registradas as suas ações, cursos realizados, 
entre outros. Já a ferramenta de busca, permite localizar algo específico com a utilização de palavras chaves.

Os demais menus são segmentados em nove abas nomeadas na por ordem da esquerda para direita, conforme constam na página, a) Conteúdos; b) Vídeos; c) Downloads; d) Doe Aqui; e) Cursos; f) Pesquisas; g) Eventos; h) "+"; e, i) "Sobre a Endeavor. Por meio do painel destes menus é possível acessar outras páginas ou mais opções de menus, e por esse motivo os conteúdos serão apresentados de acordo com essas especificações.

Assim ao clicar sobre as abas: b) Vídeos; c) Downloads; d) e) Cursos; f) Pesquisas; e, g) Eventos, o usuário é direcionado a outras informações. No menu (b) Vídeos, é possível acessar conteúdos em formato de imagem e audio, independentemente de sua área temática. Em (c) Downloads, (d) Doe Aqui e (e) Cursos, tratam-se da mesma abordagem já apresentada na sessão anterior, por meio do acesso pela página inicial. $\mathrm{O}$ ambiente (f) voltado às Pesquisas apresenta uma série de materiais, que podem ser acessados na página inicial, no Ambiente Empreendedor já abordado na primeira etapa desta pesquisa, mas também outros, em parceria com variadas instituições. O último item desta análise são os (g) Eventos, um ambiente de aprendizado prático, no qual são elencadas possibilidades de participação à distância presencial em diversas atividades.

Em relação aos itens, (a) Conteúdos; h) "+"; e, i) "Sobre a Endeavor, ao se posicionar o cursor do mouse sobre uma das informações pertinentes ao menu, abre-se um menu secundário, no qual estão dispostas outras séries alternativas de navegação. O acesso a (a) Conteúdos, é formado pelos menus secundários, i) inspiração; ii)Startups; iii) Crescimento; iv) Pessoas; v)Operações; vi) Capital; vii) Vídeos, e viii) Downloads. Os quais por sua vez, dispõem de mais um menu de opções.

Acessando-se (i) inspiração os hiperlinks direcionam o usuário ao menu no qual estão disponíveis as opções Cases Endeavor e Grandes Líderes. Ao clicar em (ii) Startups o usuário é direcionado a um menu, com as opções, Ideias de negócio, Modelo de negócios, Desenvolvimento de Produto, Pitch e Funding. Em (iii) Crescimento os o usuário é direcionado às opções: Planejamento estratégico, Inovação, Marketing, Vendas, Expansão de mercado. A aba (iv) Pessoas é composta pelos conteúdos: Sócios, Liderança, Cultura organizacional, Contratação e 
Desenvolvimento. As (v) Operações direcionam o usuário as opções: Gestão, Finanças, Jurídico e Tecnologia. (vi) Capital é o menu composto por: Bootstraping, Investidores anjo, Fundos de investimento, Linhas de fomento e Empréstimo. No Menu (vii) Vídeos estão disponíveis as opções Day 1, CEO Summit, Sonho Grande, Vai que dá, Entrevistas e Palestras. E, o menu (ix) Downloads direciona o usuário a E-books, Planilhas e templetes, Pesquisas.

A aba "Crescimento" apresenta um série de abordagens voltadas à modelos que implicam na expansão de empreendimentos. Já a aba "Pessoas" é destinada ao desenvolvimento pessoal, agregando conteúdos voltados á lideranças e programas de trainee, e intraempreendedorismo, dentre outros. Já a opções "Operações" inclui as áreas gerenciais, financeira, questões jurídicas incluindo abertura e fechamento de empresas e a utilização da internet para alavancar os negócios. A aba capital apresenta algumas semelhanças com o menu funding, já apresentado em "Inspiração", neste ponto no entanto, busca-se também o gerenciamento e destinação dos recursos.

A última categoria de análise elencada destaca os elementos: $(h)+e(i)$ Sobre a Endeavor, os quais possuem apenas um menu secundário. Acessando-se (h) + é possível identificar quatro subitens, representados por "Empreendedores Endeavor, Promessas Endeavor, Bota pra fazer e Visão de Sucesso". Somente a página "Visão de Sucesso" não pode ser acessada, com informação de erro por e página não localizada, as demais, foram direcionadas aos conteúdos. Com relação aos "Empreendedores Endeavor" é apresentada uma síntese da história de empreendedores que tem ligação com a Endeavor, sendo possível inclusive visualizar a foto do empreendedor (a). "Bota pra Fazer" é um treinamento online que visa criação de negócios de alto impacto e permite a identificação de oportunidades por parte do empreendedor. Com relação a aba "Promessas Endeavor", já foi abordado na sessão Interface Gráfica: página principal do website Endeavor Brasil.

Acessando-se (i) Sobre a Endeavor, o usuário é direcionado à páginas voltadas ao histórico da empresa. Quanto mencionado "Quem Apoia", é possível visualizar os parceiros e apoiadores da Endeavor Brasil. Conforme Endeavor Brasil (2016) os parceiros são a organização que "acreditam na causa do empreendedorismo de alto impacto e acolhem projetos, programas e produtos da Endeavor Brasil, oferecendo o recurso necessário para que eles existam e gerem 
um impacto cada vez maior na sociedade". Assim, a Endeavor também define seus apoiadores como "organizações que oferecem os serviços e produtos essenciais para que a gente consiga realizar todas as nossas iniciativas com excelência". Dentre os parceiros pode-se citar FMFBOVESPA, Bradesco, Google, Itaú, Santander, Sebrae, IBGE, DELL, FINEP, entre outros. Entre os apoiadores empresas como AmBev, Localiza, SENAI, Yahoo, 3 corações, dentre outras. Os apoiadores e parceiros também dão credibilidade às ações Endeavor.

É possível perceber que ao se navegar pela página variados caminhos levam o usuário a um mesmo conteúdo, tornando por vezes o acesso um tanto confuso e cansativo, em contrapartida percebe-se também uma página intuitiva e de fácil navegação que instiga o usuário a continuar buscando por variados conteúdos,

Percebeu-se dentre as alternativas disponíveis no website grande utilização das redes sociais como forma de difusão desses conhecimentos.

\section{CONSIDERAÇÕES FINAIS}

A Endeavor Brasil é uma organização com apenas 16 anos, e já representa um grande referencial para diversos empreendedores, em modelos de gestão e alavancagem de negócios, falar em empreendedorismo atualmente sem mencionar a Endeavor é praticamente inimaginável. Em meio á cultura digital o website da empresa representa um meio de interação com usuários, buscando atingir a missão a qual se propõe de disseminando uma cultura empreendedora.

O meio Digital para organização apresenta fatores essenciais para sua estrutura e comunicação e interação com seu público alvo. Trata-se de um portal de aprendizagem no qual casos empíricos são apresentados como fontes de inspiração, e a variedade de conteúdos a serrem acessados são escolhidos conforme as necessidades do usuário.

Exceto com inúmeros retalhos seria possível fazer uma análise criteriosa de todos os conteúdos disponibilizados pela Endeavor, mas a partir dos dados apontados nesta pesquisa percebeu-se que um alto comprometimento da organização com sua missão institucional de formar um mundo mais empreendedor.

Para futuras pesquisas sugere-se análises relacionadas aos conceitos de User Experiense, métricas de marketing digital, bem como análises mais aprofundadas dos conteúdos específicos, desenvolvidos em parceria entre a 
Endeavor e outras instituições como Sebrae, IBGE por exemplo. Para futuras pesquisas sugere-se também, análises em outras plataformas existentes com foco em ensino, como "Khan Academy".

\section{REFERÊNCIAS}

BUCKINGHAM, D. Cultura digital, educação midiática e o lugar da escolarização. Educação \& Realidade, v. 35, n. 3, 2010.

CASTELLS, M. A sociedade em Rede - A era da informação: economia, sociedade e cultura, Vol. 1. São Paulo: Paz e Terra, p. 17-49, 1999.

DIAS, P. Comunidades de educação e inovação na sociedade digital. Educação, Formação \& Tecnologias, v. 5, n. 2, p. 4-10, 2012.

ENDEAVOR. Disponível em: <http://endeavor.org/> Acesso em: 07 mar. 2016.

LÉVY, P. Cibercultura [Cyberculture]. São Paulo: Ed, v. 34, 2000.

PRETTO, N.L.; ASSIS, A. Cultura digital e educação: redes já. Além das redes de colaboração: internet, diversidade cultural e tecnologias do poder. Salvador: EDUFBA, p. 75-84, 2008.

SILVA, B.D.; DUARTE, E. C. V. G.; SOUZA, K. P. Tecnologias digitais de informação e comunicação: artefatos que potencializam o empreendedorismo da geração digital. 2013.

SOUZA, K. P. D., MOURA, A., \& SILVA, B. D. D. Desenvolvimento de inovações pedagógicas para o currículo de empreendedorismo digital em Portugal. 2013. 